\title{
Editorial
}

\section{Os Caminhos da Saúde Coletiva}

| Kenneth Rochel de Camargo Jr. |

O tema desta edição de Physis retorna à reflexão sobre o campo da Saúde Coletiva. O desenvolvimento teórico e metodológico da Saúde Coletiva, a institucionalização da mesma nos programas de pós-graduação, sua contribuição para a construção de uma política de saúde que faça valer de fato os valores inscritos em nossa Carta Magna são o pano de fundo dessa discussão. Dado o estabelecimento de uma lógica competitiva excludente por parte das agências das áreas de C\&T e educação pós-graduada no país, contudo, essa discussão tem sido reduzida progressivamente aos processos avaliativos daquelas agências. A corrida cega em busca das "melhores notas" tem implicaçôes e repercussôes que talvez não estejam plenamente em sintonia com os princípios éticos e políticos dos quais a Saúde Coletiva brasileira é herdeira histórica. Nossa revista tem procurado dar relevo, ainda que correndo o risco de parecer repetitiva, às questóes políticas e epistemológicas maiores que sobredeterminam tais processos avaliativos, e é nesse sentido que apresentamos o tema da presente edição.

No primeiro artigo do tema, Rita Barata, nossa representante frente à CAPES e editora da Revista de Saúde Pública, apresenta balanço encorajador da área, ainda que apontando alguns desafios críticos para a mesma. Destaco em particular a questão da inadequação do modelo de avaliação de produção científica ao conjunto da Saúde Coletiva, questão que tem sido constantemente levantada em vários artigos e editoriais publicados na Physis, e a tensão interna gerada no campo por conta deste problema, o que também apontávamos no editorial do primeiro número do volume 15 de Physis.

No segundo, Maria Andrea Loyola, professora titular do IMS, apresenta uma perspectiva crítica sobre o desenvolvimento histórico da Saúde Coletiva como campo de pesquisa, ensino e ação política, com ênfase nas relações do campo 
com as agências de fomento, por um lado, e na interação interna entre suas subáreas, por outro.

Encerrando o tema, Ana Maria Canesqui, coordenadora da então Comissão de Ciências Sociais da Abrasco de 1994 a 1996, descreve e analisa a trajetória da mesma (atualmente Comissão de Ciências Sociais e Humanas). Através da reflexão histórica sobre o processo de institucionalização da comissão no interior da associação científica da área de Saúde Coletiva, Canesqui nos permite acompanhar a própria dinâmica interna às ciências sociais e humanas e sua relação com o campo mais amplo da Saúde Coletiva. Ao descrever e situar teoricamente, a partir de Bourdieu, a contraposição entre "puros" e "híbridos", a autora sinaliza talvez para a reprodução no interior de uma subárea dos conflitos de legitimação e hegemonia observados na relação entre as subáreas da Saúde Coletiva.

Como ocorre com todo tema complexo, há uma natural e saudável divergência de perspectivas entre os artigos temáticos deste número. Em parte isto se deve à natureza fluida do próprio campo, que se deseja interdisciplinar e necessariamente aberto a contribuições diversas, mas que ao mesmo tempo busca a especificidade temática de uma área autônoma e demarcada. Essa tensão estrutural coloca desafios particulares para a reflexão sobre a Saúde Coletiva, além de deixar claros os obstáculos para que a mesma se desenhe como área interdisciplinar de fato.

Exatamente por conta desses desafios, parece-nos óbvia a necessidade do debate constante sobre a Saúde Coletiva que desejamos. A própria área sinaliza para isso, com a expressiva produção que procura pensar o próprio campo, bem como nos espaços institucionais - como o Fórum de Coordenadores de Pós-Graduação, os congressos realizados pela Abrasco e a própria dinâmica interna das suas comissões e GTs - constantemente a problematizar a temática. Nós, da Physis, temos procurado estimular esta discussão, mas acreditamos ser necessário que mais vozes participem da mesma. Nesse sentido, convidamos nossos leitores e colaboradores a enviarem suas cartas, comentando os artigos deste tema ou quaisquer outros que desejem, para inaugurar a nossa seção de cartas a partir do próximo número.

Zambenedetti e Perrone abrem os temas livres com o estudo da implantação de uma rede de atenção em Saúde Mental em Santa Maria, Estado do Rio Grande do Sul. A partir do estudo de um caso concreto, os autores mostram os desafios 
enfrentados na transformação do ideário da Reforma Psiquiátrica em medidas concretas de atenção, apontando para problemas (como a fragilidade dos mecanismos de referência e contra-referência) não muito diferentes dos observados nas miríades de experiências de implantaçooes locais do SUS, do qual a Saúde Mental, nunca é demais lembrar, é parte fundamental.

No artigo seguinte, Barreto continua no tema da saúde mental, explorando, apoiado em Hannah Arendt, os conceitos de cidadania e subjetividade como operadores de uma releitura teórica e ética das propostas de reforma psiquiátrica.

Miguelote et al. abordam um aspecto crítico da saúde global, a má distribuição mundial da força de trabalho em saúde, problema particularmente severo no continente africano que, além da carência de profissionais, ainda experimenta os efeitos contínuos de um brain drain que atrai os mais qualificados para as antigas metrópoles coloniais. As autoras destacam a necessidade da inclusão dessa temática nas negociações multilaterais na área econômica, outra arena onde os processos da globalização têm produzido e ampliado as desigualdades entre países e povos.

A percepção de risco entre motoboys de Londrina, Estado do Paraná, é o tema do artigo de Silva et. al. A partir de dados obtidos em um grupo focal, os autores mostram como, de forma muito concreta, as desigualdades das relações econômicas se transformam em vulnerabilidade - todos os participantes do estudo relataram o envolvimento em acidentes.

No encerramento da seção, Honorato e Pinheiro descrevem o trabalho de profissionais de saúde mental junto a uma comunidade específica como parte do processo de desinstitucionalização dos pacientes de um hospital psiquiátrico de Carmo, cidade do interior do Estado do Rio de Janeiro. Uma das questóes apontadas pelos autores é a da relevância da perspectiva da reinserção social daqueles pacientes como questão fundamental para o processo da Reforma Psiquiátrica. Nesse sentido, o trabalho da equipe multiprofissional com a comunidade de referência é tão ou mais estratégico quanto a atividade clínica junto aos primeiros.

$\mathrm{Na}$ seção de resenhas, Rangel analisa o livro Saúde, Corpo e Sociedade: a importância da interdisciplinaridade na formação dos profissionais de saúde, organizado por Alicia Navarro de Souza e Jacqueline Pitanguy. 